Embedding open and reproducible science into teaching: A bank of lesson plans and resources

Madeleine Pownall ${ }^{1}$, Flavio Azevedo ${ }^{2}$, Alaa Aldoh $^{3}$, Mahmoud Elsherif $^{4}$, Martin Vasilev $^{5}$, Charlotte R. Pennington ${ }^{6}$, Olly Robertson ${ }^{7}$, Myrthe Vel Tromp ${ }^{8}$, Meng Liu ${ }^{9}$, Matthew C. Makel $^{10}$, Natasha Tonge ${ }^{11}$, David Moreau ${ }^{12}$, Ruth Horry ${ }^{13}$, John Shaw ${ }^{14}$, Loukia Tzavella ${ }^{15}$, Ronan McGarrigle ${ }^{16}$, Catherine Talbot ${ }^{5}$, FORRT $^{17}$, and Sam Parsons ${ }^{7}$.

1. University of Leeds, UK

2. Friedrich Schiller University

3. University of Sussex, UK

4. University of Birmingham, UK

5. Bournemouth University, UK

6. Aston University, Birmingham, UK

7. University of Oxford, UK

8. Leiden University, the Netherlands

9. University of Cambridge, UK

10. Johns Hopkins University, USA

11. Notre Dame of Maryland University

12. University of Auckland

13. Swansea University

14. De Montfort University, UK

15. Cardiff University, UK

16. University of Bradford, UK

17. Framework for Open and Reproducible Research Training 


\begin{tabular}{|c|c|c|c|c|c|c|}
\hline Name & $\begin{array}{l}\text { Email } \\
\text { address }\end{array}$ & Affiliation & $\begin{array}{l}\text { Lesson } \\
\text { plan } \\
\text { contribut } \\
\text { or }\end{array}$ & $\begin{array}{l}\text { Activity } \\
\log \\
\text { contributor }\end{array}$ & $\begin{array}{l}\text { Manuscript } \\
\text { editor }\end{array}$ & Orcid ID \\
\hline $\begin{array}{l}\text { Madeleine } \\
\text { Pownall }\end{array}$ & $\begin{array}{l}\text { M.V.Pown } \\
\text { all@ leeds. } \\
\text { ac.uk }\end{array}$ & $\begin{array}{l}\text { University } \\
\text { of Leeds, } \\
\text { UK }\end{array}$ & $X$ & $X$ & $X$ & $\begin{array}{l}\text { 0000-0002- } \\
3734-8006\end{array}$ \\
\hline $\begin{array}{l}\text { Flavio } \\
\text { Azevedo }\end{array}$ & $\begin{array}{l}\text { flavio.azev } \\
\text { edo@ @uni- } \\
\text { jena.de }\end{array}$ & $\begin{array}{l}\text { Friedrich } \\
\text { Schiller } \\
\text { University }\end{array}$ & $X$ & & $X$ & $\begin{array}{l}0000-0001- \\
9000-8513\end{array}$ \\
\hline $\begin{array}{l}\text { Alaa } \\
\text { Aldoh }\end{array}$ & $\begin{array}{l}\text { a.aldoh@s } \\
\text { ussex.ac.u } \\
\text { k }\end{array}$ & $\begin{array}{l}\text { University } \\
\text { of Sussex, } \\
\text { UK }\end{array}$ & & $X$ & $X$ & $\begin{array}{l}0000-0003- \\
1988-0661\end{array}$ \\
\hline $\begin{array}{l}\text { Mahmoud } \\
\text { Elsherif }\end{array}$ & $\begin{array}{l}\text { mahmoud. } \\
\text { medhat.els } \\
\text { herif@gma } \\
\text { il.com }\end{array}$ & $\begin{array}{l}\text { University } \\
\text { of } \\
\text { Birmingha } \\
\text { m }\end{array}$ & $X$ & $X$ & $X$ & $\begin{array}{l}0000-0002- \\
0540-3998\end{array}$ \\
\hline $\begin{array}{l}\text { Martin } \\
\text { Vasilev }\end{array}$ & $\begin{array}{l}\text { mvasilev@ } \\
\text { bournemo } \\
\text { uth.ac.uk }\end{array}$ & $\begin{array}{l}\text { Bournemout } \\
\text { h University }\end{array}$ & $X$ & $X$ & $X$ & $\begin{array}{l}0000-0003- \\
1944-8828\end{array}$ \\
\hline $\begin{array}{l}\text { Charlotte } \\
\text { R. } \\
\text { Penningto } \\
\text { n }\end{array}$ & $\begin{array}{l}\text { c.penningt } \\
\text { on @ aston. } \\
\text { ac.uk }\end{array}$ & $\begin{array}{l}\text { Aston } \\
\text { University, } \\
\text { Birmingha } \\
\text { m, UK }\end{array}$ & $X$ & $X$ & $X$ & $\begin{array}{l}\text { 0000-0002- } \\
5259-642 X\end{array}$ \\
\hline $\begin{array}{l}\text { Olly } \\
\text { Robertson }\end{array}$ & $\begin{array}{l}\text { olly.robert } \\
\text { son@ @psyc } \\
\text { h.ox.ac.uk }\end{array}$ & $\begin{array}{l}\text { University } \\
\text { of Oxford, } \\
\text { UK }\end{array}$ & & & $X$ & $\begin{array}{l}\text { 0000-0002- } \\
7333-0903\end{array}$ \\
\hline $\begin{array}{l}\text { Myrthe } \\
\text { Vel Tromp }\end{array}$ & $\begin{array}{l}\text { m.j.b.vel.tr } \\
\text { omp@ uma } \\
\text { il.leidenuni } \\
\text { v.nl }\end{array}$ & $\begin{array}{l}\text { Leiden } \\
\text { University, } \\
\text { the } \\
\text { Netherlands }\end{array}$ & $X$ & $X$ & $X$ & $\begin{array}{l}\text { 0000-0002- } \\
2076-5348\end{array}$ \\
\hline Meng Liu & $\begin{array}{l}\text { ml858@ca } \\
\text { m.ac.uk }\end{array}$ & $\begin{array}{l}\text { University } \\
\text { of } \\
\text { Cambridge, } \\
\text { UK }\end{array}$ & $X$ & $X$ & $X$ & $\begin{array}{l}\text { 0000-0001- } \\
8323-2699\end{array}$ \\
\hline $\begin{array}{l}\text { Matthew } \\
\text { C. Makel }\end{array}$ & $\begin{array}{l}\text { makel@jh } \\
\text { u.edu }\end{array}$ & $\begin{array}{l}\text { Johns } \\
\text { Hopkins } \\
\text { University, } \\
\text { USA }\end{array}$ & $X$ & $X$ & $X$ & $\begin{array}{l}\text { 0000-0002- } \\
3837-0088\end{array}$ \\
\hline
\end{tabular}




\begin{tabular}{|c|c|c|c|c|c|c|}
\hline $\begin{array}{l}\text { Natasha } \\
\text { Tonge }\end{array}$ & $\begin{array}{l}\text { natasha.ton } \\
\text { ge@ gmail. } \\
\text { com }\end{array}$ & $\begin{array}{l}\text { Notre Dame } \\
\text { of Maryland } \\
\text { University }\end{array}$ & & & $X$ & $\begin{array}{l}0000-0001- \\
7670-7991\end{array}$ \\
\hline $\begin{array}{l}\text { David } \\
\text { Moreau }\end{array}$ & $\begin{array}{l}\text { d.moreau } \\
\text { @ auckland } \\
\text {.ac.nz }\end{array}$ & $\begin{array}{l}\text { University } \\
\text { of Auckland }\end{array}$ & & & $X$ & $\begin{array}{l}0000-0002- \\
1957-1941\end{array}$ \\
\hline $\begin{array}{l}\text { Ruth } \\
\text { Horry }\end{array}$ & $\begin{array}{l}\text { r.horry@s } \\
\text { wansea.ac. } \\
\text { uk }\end{array}$ & $\begin{array}{l}\text { Swansea } \\
\text { University }\end{array}$ & $X$ & & $X$ & $\begin{array}{l}\text { 0000-0003- } \\
3105-3781\end{array}$ \\
\hline John Shaw & $\begin{array}{l}\text { john.shaw } \\
@ \text { dmu.ac. } \\
\text { uk }\end{array}$ & $\begin{array}{l}\text { De } \\
\text { Montfort } \\
\text { University, } \\
\text { UK }\end{array}$ & $X$ & & $X$ & $\begin{array}{l}0000-0003- \\
3190-6772\end{array}$ \\
\hline $\begin{array}{l}\text { Loukia } \\
\text { Tzavella }\end{array}$ & $\begin{array}{l}\text { tzavellal@ } \\
\text { cardiff.ac. } \\
\text { uk }\end{array}$ & $\begin{array}{l}\text { Cardiff } \\
\text { University, } \\
\text { UK }\end{array}$ & $X$ & $X$ & $X$ & $\begin{array}{l}0000-0002- \\
1463-9396\end{array}$ \\
\hline $\begin{array}{l}\text { Ronan } \\
\text { McGarrigl } \\
\text { e }\end{array}$ & $\begin{array}{l}\text { r.mcgarrigl } \\
\text { e@ bradfor } \\
\text { d.ac.uk }\end{array}$ & $\begin{array}{l}\text { University } \\
\text { of Bradford, } \\
\text { UK }\end{array}$ & $X$ & $X$ & $X$ & $\begin{array}{l}0000-0003- \\
1704-1135\end{array}$ \\
\hline $\begin{array}{l}\text { Catherine } \\
\text { Talbot }\end{array}$ & $\begin{array}{l}\text { Ctalbot@b } \\
\text { ournemout } \\
\text { h.ac.uk }\end{array}$ & $\begin{array}{l}\text { Bournemout } \\
\text { h } \\
\text { University, } \\
\text { UK }\end{array}$ & $X$ & & $X$ & $\begin{array}{l}\text { 0000-0001- } \\
9353-8990\end{array}$ \\
\hline FORRT & $\begin{array}{l}\text { projectFO } \\
\text { RRT@,forr } \\
\text { t.org }\end{array}$ & $\begin{array}{l}\text { Framework } \\
\text { for Open } \\
\text { and } \\
\text { Reproducibl } \\
\text { e Research } \\
\text { Training }\end{array}$ & $X$ & $X$ & $X$ & $\begin{array}{l}\text { 0000-0002- } \\
7562-5342\end{array}$ \\
\hline $\begin{array}{l}\text { Sam } \\
\text { Parsons }\end{array}$ & $\begin{array}{l}\text { sam.parson } \\
\text { s@ @ psy.ox. } \\
\text { ac.uk }\end{array}$ & $\begin{array}{l}\text { University } \\
\text { of Oxford, } \\
\text { UK }\end{array}$ & $X$ & & $X$ & $\begin{array}{l}\text { 0000-0002- } \\
7048-4093\end{array}$ \\
\hline
\end{tabular}




\title{
Embedding open and reproducible science into teaching: A bank of lesson plans and resources
}

\begin{abstract}
Recently, there has been a growing emphasis on embedding open and reproducible approaches into research. One essential step in accomplishing this larger goal is to embed such practices into undergraduate and postgraduate research training. However, this often requires substantial time and resources to implement. Also, while many pedagogical resources are regularly developed for this purpose, they are not often openly and actively shared with the wider community. The creation and public sharing of open educational resources is useful for educators who wish to embed open scholarship and reproducibility into their teaching and learning. In this article, we describe and openly share a bank of teaching resources and lesson plans on the broad topics of open scholarship, open science, replication, and reproducibility that can be integrated into taught courses, to support educators and instructors. These resources were created as part of the Society for the Improvement of Psychological Science (SIPS) hackathon at the 2021 Annual Conference, and we detail this collaborative process in the article. By sharing these open pedagogical resources, we aim to reduce the labour required to develop and implement open scholarship content to further the open scholarship and open educational materials movement.
\end{abstract}

Keywords: open educational resources; open science; open scholarship; pedagogy; reproducibility 


\section{Embedding open and reproducible science into teaching: A bank of lesson plans and}

\section{resources}

\section{Background}

Open scholarship (which incorporates open science and open research) is a framework that aims to improve the reproducibility, replicability, transparency, and robustness of research (Asendorpf et al., 2013; Crüwell et al., 2019; Kathawalla et al., 2021; Munafò et al., 2017; Parsons et al., 2021). In the shift towards a more 'open' way of doing research, there have been concerns about questionable research practices (QRPs), which include, for example, selective reporting of results, generating hypotheses after finding significant results, and concealing conflicts of interest. QRPs can be reduced by improving the openness, rigour, and transparency of research. Tools to reduce QRPs include preregistration of a study's hypotheses and analysis plan prior to data collection and/or analyses (e.g., Lindsay et al., 2016; Nosek et al., 2015), open data sharing (Houtkoop et al., 2018), considering meta-analytical perspective (Topor et al., 2020) and a focus on replication studies to evaluate the robustness of key findings and scientific theories (Open Science Collaboration, 2015; Tierney et al., 2020, 2021). Although this movement has been primarily informed by a quantitative perspective, qualitative researchers are also considering how they can adopt more open practices (e.g., Haven \& van Grootel, 2019; Haven et al., 2020).

To date, the conversations concerning open scholarship have predominantly centred on improving research practices. However, more recently, there has been a push for embedding open and reproducible research into undergraduate and postgraduate research training. There is also a plethora of recent evidence that supports the need for incorporating this approach into undergraduate and postgraduate training (e.g., Button, 2018; FORRT, 2019; Pownall, 2020). This has led to discussions related to teaching undergraduate students about the factors that have contributed to the 'replication crisis', which is the growing 
concern about the lack of successful replications of published research (Chopik et al., 2018; Haas \& Rouse, 2020). Similarly, there have been efforts to address QRPs in student research (Sacco \& Brown, 2019; Strand \& Brown, 2019; Wagge et al., 2019), and considerations of how to integrate this approach across teaching curricula (Frank \& Saxe, 2012; Frankowski, 2021; Galati \& Markant, 2018; Hanna et al., 2021; Sarafoglou et al., 2020). Likewise, there have been recent proposals to respond to these concerns through development of best practice guides (e.g., Morling \& Calin-Jageman, 2020; Stojmenovska et al., 2019) and dissemination of novel ways to teach open scholarship methods and concepts (Jekel et al., 2020). An exemplar of this approach is the Framework for Open and Reproducible Research Teaching (FORRT; www.forrt.org); established in 2018, FORRT is a community-led group that promotes the incorporation of open, transparent, and reproducible scholarship in research training at all levels (FORRT, 2019).

\section{The need for open educational resources}

Open scholarship has prompted a fundamental reappraisal of how we 'do' research, by stressing the importance of a culture that fosters inclusion, representation, and respect (FORRT, 2019; Hillyer et al., 2017; Nosek et al., 2015; Parsons et al., 2021; Pownall et al., 2021). However, despite the clear pedagogical benefits of embedding an open and reproducible approach to teaching, the implementation of any new approach often requires considerable time and resources to implement. Given these costs, efforts to reduce barriers to entry are beneficial to educators and also contribute to sharing and promoting best practice. Open educational resources (OERs) are freely-available resources for educators and students that are designed to be adapted for local unique contexts (Smith, 2009). The creation and sharing of OERs has been thought to mitigate logistical and accessibility barriers to implementation of best practice in teaching at local levels (Mishra, 2017). They can thus be particularly helpful for precariously employed educators who are not afforded large amounts 
of time for lesson planning and engagement with pedagogical literature, such as adjunct professors, doctoral instructors, or graduate teaching assistants. OERs also have a strong emphasis on improving social justice, accessibility and inclusion (Baker \& Sibona, 2020; Conole, 2012), because they democratise access to educational resources and thus improve access to educational tools. That is, the current (closed) model of scientific production and educational practices perpetuates existing academic power structures and accessibility inequities, thereby alienating the socially and geographically marginalised. To mitigate these detrimental effects on the access to-and maximize students' engagement with-scientific content and educational materials, there have been calls for the creation of "conditions for knowledge to become a public good—accessible to all members of society" (FORRT, 2019, p. 12).

As Clinton (2019) proposed, OERs in psychology are also beneficial because they remove the logistical barriers of educators designing their own materials from scratch, which also serves to democratize access to educational knowledge and resources (FORRT, 2019). As such, OERs have been championed in the open scholarship conversation. For example, Egan and colleagues (2020) describe the Principles and Practices of Open Research: Teaching, Research, Impact, and Learning (PaPOR TRaIL) project that aims to develop an OER for teaching open research through interviews and student surveys. OERs have the capacity to foster uptake of new pedagogies, promote best practice, and reduce workload constraints of educators who wish to embed new approaches to teaching and learning. Open sharing of educational resources is well aligned with the spirit of wider open scholarship initiatives, particularly when OERs are Findable, Accessible, Interoperable, and Reusable (FAIR; Crüwell et al., 2019; Wilkinson et al., 2016).

\section{Resources, activities, and lesson plans}


We created a bank of pedagogical activities, resources, and crowdsourced lesson plans that educators can use as stand alone material or as supplementary material within existing lesson plans to embed an open and reproducible approach to their learning and teaching practices. These resources and activities were also designed to be embedded in any teaching context irrespective of the level of open scholarship that already exists in the local curriculum. The bank was inspired by other articles that share useful resources for psychology educators (e.g., Beins, 2020; Lilienfeld et al., 2001). The resources and lesson plans shared here are the product of a three-hour 'hackathon' held at the Society for the Improvement for Psychological Science (SIPS; https://improvingpsych.org/) Annual Conference in June 2021. Led by members of FORRT (see FORRT, 2019), members of the open scholarship community collaboratively compiled a bank of existing pedagogical activities and resources that educators may wish to use in their teaching. Contributors were from all over the world, at various career stages, all with mixed experiences of undergraduate and postgraduate teaching in different contexts. These resources include, for example, interactive activities that demonstrate to students the difference between causality and correlation, published papers that are ripe for in-class discussions about replication and open science practices, and open-source software packages that enable students to practice open scholarship. The resources were compiled from a number of educators' own teaching practice, as well as social media, published practice exchanges, and scholarly teaching articles (e.g., in journals such as Scholarship of Teaching and Learning in Psychology, Teaching of Psychology, and Psychology Teaching Review).

We then translated this bank of activities and resources into fully-developed, usable, and accessible lesson plans for educators to adapt to their own unique context. A 'lesson plan', in this context, is a short description of how a given resource could be implemented in the classroom; for example, outlining different exercises or techniques that can be directly 
used by the educator and their associated learning objectives and timings. This focus on 'classroom ready' lesson plans is in direct response to concerns that OERs are overly concerned with content over delivery or implementation of activities (e.g., Knox, 2013). This is problematic because it still relies on educators grappling with the implementation of content, and thus does not fully align with the spirit of OERs as 'classroom ready' resources. The bank of resources, activities, and lesson plans can be freely accessed from our Open Science Framework page: https://osf.io/th254/.

Table 1 details our example lesson plans that were developed as part of this virtual hackathon, each with distinct learning outcomes and a link to an openly accessible example. These lesson plans were designed in groups ranging from 1-5 delegates in breakout rooms of the virtual hackathon. The theme of each lesson plan was left open, and the collection of lesson plans aimed to cover the breadth of open scholarship and reproducibility. Some of these centred around specific research skills (e.g., Lesson plan 1; interpreting effect sizes and confidence intervals), whereas others focused more broadly on teaching open and reproducible science explicitly (e.g., Lesson plan 2), including covering different epistemologies and methodologies in science (e.g., Lesson plan 7).

Table 1. Overview of open and reproducible research lesson plans

\begin{tabular}{|c|c|c|c|}
\hline Number & Lesson plan title & Learning outcomes & Link \\
\hline 1 & $\begin{array}{l}\text { Interpreting effect } \\
\text { sizes and confidence } \\
\text { intervals }\end{array}$ & $\begin{array}{l}\text { 1. To understand that confidence } \\
\text { intervals are an important addition } \\
\text { to p-value research. } \\
\text { 2. To understand how to meaningfully } \\
\text { interpret confidence intervals. } \\
\text { 3. To get hands-on experience with } \\
\text { visualization. } \\
\text { 4. To understand the meaning of } \\
\text { effect size and how it is calculated. }\end{array}$ & $\begin{array}{l}\text { https://osf.i } \\
\text { o/8jmbu/ }\end{array}$ \\
\hline
\end{tabular}


1. To understand replication within

https://osf.i

the scientific method.

o/2znr4/

2. To distinguish direct/exact and conceptual replications.

3. To understand contemporary issues in psychology i.e., the replication crisis and open science.

4. To critically assess original research findings and replication attempts. (not cynical)

1. Understand the difference between https://osf.i critical and cynical perspectives o/7qz38/ about research evidence.

2. Develop and use criteria for evaluating replicability of research evidence.

3. Apply a critical-not-cynical approach to evaluating research evidence.

$4 \quad$ Introduction to Open Science

1. Introduction to (the importance of) open research practices

https://osf.i $\mathrm{o} / \mathrm{x} 3 \mathrm{~m} 9 \mathrm{k} /$

2. Understanding that science is fallible

1. Equip students with basic understanding of methodological and statistical issues associated with replicability issues

2. Understand how $p$-hacking can occur, and the impact on the literature

3. Examine how low power influences observed effect sizes and the false positive rate

4. Equip students to identify issues around p-hacking, low power, false positive rates, optional stopping https://osf.i o/cwaqj/ 
6 Dodgy research
papers

7

Research paradigms and open science

Open data and qualitative research

9

Diversity and inclusion in (br)open science

8 qualitave reseach

inclusion in
(br)open science

1. Identify methodological and analytical problems.

2. Identify associated reliability and validity problems.

3. More broadly, learn not to necessarily trust every published research paper.

1. Develop a more holistic and critical https://osf.i understanding of open science.

2. Identify and/or address potential concerns and/or misconceptions about open science.

3. Promote epistemological pluralism.

1. To understand the challenges of applying Open Science principles to qualitative research o/r8ymj/

https://osf.i

o/hrzwj/

2. To critically evaluate the impact of applying open data principles to qualitative research

https://osf.i o/nyfqx/

1. To increase students' understanding https://osf.i of the importance of recognising and celebrating diverse voices in psychology

2. To appreciate the need for science to be inclusive and welcoming

3. To address barriers within (br)open science

\section{Reflections and Future Directions}

In this article, we have described and shared a bank of OERs that aim to help educators embed open and reproducible research into their teaching. Although many of these resources and activities already exist, sifting through resources and the process of translating a resource into a lesson plan or class activity requires both effort and expertise. Here, we have 
synthesised, simplified, and collated OERs to help other educators who wish to incorporate this approach. This embodies the expansion from open science to open scholarship. Furthermore, the process of completing this hackathon has evidenced that power can be harnessed from groups of people working collaboratively on pedagogical problems. We hope this resource will be useful for all educators, especially those who are precariously employed and thus have little time to engage with the pedagogical literature to find or create appropriate teaching resources. Indeed, while evidence suggests that early career scholars and educators are among the most engaged with the open scholarship movement (e.g., Pownall et al., 2021), there are systemic and logistical barriers, related to time and availability of resources, that may preclude embedding these values within teaching practice.

It is important to note here that we do not consider this bank to be fixed, or even 'finished'. Rather, we invite other educators to contribute to the bank of resources, take our lesson plans and mold them to their own unique context, and provide feedback on the current entries. To facilitate that, we also provide a lesson plan template and editable version of our bank of resources (https://osf.io/th254/). These materials will also be featured in the FORRT lesson plans, as part of the educational nexus of the FORRT project (FORRT, 2019; ttps://forrt.org/nexus/). Here, educators can also access relevant background reading on open scholarship, which may inspire more contributions to this project (e.g., https://forrt.org/clusters/).

We welcome ongoing contributors to this project, particularly contributions which grapple with topics of inclusion, diversity, and accessibility of open scholarship. This may be achieved through follow-up hackathons that aim to develop and refine the resources in the bank. Refinements to the bank may include, for example, categorising entries by student level, creating alternative versions of lesson plans for different contexts, and translating resources into different languages. Similarly, we acknowledge that whilst the contributorship 
of this project is vast and international, the members of this project currently largely reflect White, Western, neurotypical perspectives that occupy certain privileges. We also, therefore, invite contributions that arrive at open scholarship from more diverse and intersectional perspectives that differ from the Western lens of the current bank of activities.

Overall, given teachers' and researchers' substantial time constraints, which pose a challenge to developing course materials and integrating new research practices in teaching, there is a need to develop strategies and solutions to mitigate time constraints and help scholars implement open and principled education in their workflows. The focus of these initiatives for creating resources should not only lie on the simple aggregation of lists and links but on building meaning between existing materials and ideas, giving them context and continuity, as well as filling in the gap where no connections exist. 


\section{References}

Asendorpf, J. B., Conner, M., De Fruyt, F., De Houwer, J., Denissen, J. J., Fiedler, K., ... \& Wicherts, J. M. (2013). Recommendations for increasing replicability in psychology. European journal of personality, 27(2), 108-119. https://doi.org/10.1002/per.1919

Baker, E. W., \& Sibona, C. J. (2020). Digital OER Impact on Learning Outcomes for Social Inclusion. Journal of Computer Information Systems, 1-11. https://doi.org/10.1080/08874417.2020.1802789

Beins, B. C. (2020). STP at 75: Development of Teaching Resources. Teaching of Psychology, 47(3), 207-214. https://doi.org/10.1177/0098628320922062

Button, K. (2018). Reboot undergraduate courses for reproducibility. Nature, 561(7723), 287 288. https://doi.org/10.1038/d41586-018-06692-8

Chopik, W. J., Bremner, R. H., Defever, A. M., \& Keller, V. N. (2018). How (and whether) to teach undergraduates about the replication crisis in psychological science. Teaching of psychology, 45(2), 158-163 .https://doi.org/10.1177/0098628318762900

Clinton, V. (2019). Cost, outcomes, use, and perceptions of open educational resources in psychology: A narrative review of the literature. Psychology Learning \& Teaching, 18(1), 4-20. https://doi.org/10.1177/1475725718799511

Conole, G. (2012). Fostering social inclusion through open educational resources (OER). Distance Education, 33(2), 131. https://doi.org/10.1080/01587919.2012.700563

Crüwell, S., van Doorn, J., Etz, A., Makel, M. C., Moshontz, H., Niebaum, J. C., Orben, A., Parsons, S., \& Schulte-Mecklenbeck, M. (2019). Seven Easy Steps to Open Science: An Annotated Reading List. Zeitschrift Für Psychologie, 227(4), 237-248.

https://doi.org/10.1027/2151-2604/a000387 
Egan, S., Tobin, M., Palmer, B., Coffey, A., Dahly, D., Houghton, C., ... \& Matvienko-Sikar, K. (2020). Developing an open educational resource for open research: Protocol for the PaPOR TRAIL project. HRB Open Research, 3.

FORRT (2019, December 13). Introducing a Framework for Open and Reproducible Research Training (FORRT). https://doi.org/10.31219/osf.io/bnh7p

Frank, M. \& Saxe, R. (2012). Teaching replication. Perspectives on Psychological Science, 7(6), 600-604. https://doi.org/10.1177/1745691612460686

Frankowski, S. D. (2021). Increasing Participation in Psychological Science by Using Course-Based Research Projects: Testing Theory, Using Open-Science Practices, and Professionally Presenting Research. Teaching of Psychology, 00986283211024200. https://doi.org/10.1177/00986283211024200

Galati, A., \& Markant, D. (2018). Examining the impact of open and transparent research practices in an undergraduate research methods course in Psychology.

Haas, H. A., \& Rouse, S. V. (2020). Learning from mistakes: Teaching students about errata, corrigenda, and nonretraction corrections to the research literature. Scholarship of Teaching and Learning in Psychology. https://doi.org/10.1037/st10000216

Hanna, S., Pither, J., \& Vis-Dunbar, M. (2021). Implementation of an Open Science Instruction Program for Undergraduates. Data Intelligence, 3(1), 150-161. https://doi.org/10.1162/dint a 00086

Haven, T., \& Van Grootel, D. L. (2019). Preregistering qualitative research. Accountability in Research, 26(3), 229-244. https://doi.org/10.1080/08989621.2019.1580147

Haven, T. L., Errington, T. M., Gleditsch, K. S., van Grootel, L., Jacobs, A. M., Kern, F. G., ... \& Mokkink, L. B. (2020). Preregistering qualitative research: a Delphi study. International Journal of Qualitative Methods, 19, 1609406920976417. 
Hillyer, R., Posada, A., Albornoz, D., Chan, L., \& Okune, A. (2017). Framing a situated and inclusive open science: emerging lessons from the open and collaborative science in development network. Expanding Perspectives on Open Science: Communities, Cultures and Diversity in Concepts and Practices, 18. https://doi.org/10.3233/978-1-61499-769-618

Houtkoop, B. L., Chambers, C., Macleod, M., Bishop, D. V., Nichols, T. E., \& Wagenmakers, E. J. (2018). Data sharing in psychology: A survey on barriers and preconditions. Advances in methods and practices in psychological science, 1(1), 70-85. https://doi.org/10.1177/2515245917751886

Jekel, M., Fiedler, S., Allstadt Torras, R., Mischkowski, D., Dorrough, A. R., \& Glöckner, A. (2020). How to Teach Open Science Principles in the Undergraduate Curriculum-The Hagen Cumulative Science Project. Psychology Learning \& Teaching, 19(1), 91-106. https://doi.org/10.1177/1475725719868149

Kathawalla, U. K., Silverstein, P., \& Syed, M. (2021). Easing into open science: A guide for graduate students and their advisors. Collabra: Psychology, 7(1), 18684. https://doi.org/10.1525/collabra.18684

Knox, J. (2013). Five critiques of the open educational resources movement. Teaching in Higher Education, 18(8), 821-832.https://doi.org/10.1080/13562517.2013.774354

Lilienfeld, S. O., Lohr, J. M., \& Morier, D. (2001). The teaching of courses in the science and pseudoscience of psychology: Useful resources. Teaching of Psychology, 28(3), 182-191. https://doi.org/10.1207/S15328023TOP2803 03

Lindsay, D. S., Simons, D. J., \& Lilienfeld, S. O. (2016). Research preregistration 101. APS observer, 29(10).

Mishra, S. (2017). Open educational resources: Removing barriers from within. Distance education, 38(3), 369-380. https://doi.org/10.1080/01587919.2017.1369350 
Morling, B., \& Calin-Jageman, R. J. (2020). What psychology teachers should know about open science and the new statistics. Teaching of Psychology, 47(2), 169-179. https://doi.org/10.1177/0098628320901372

Munafò, M. R., Nosek, B. A., Bishop, D. V., Button, K. S., Chambers, C. D., Du Sert, N. P., ... \& Ioannidis, J. P. (2017). A manifesto for reproducible science. Nature Human Behaviour, 1(1), 1-9. https://doi.org/10.1038/s41562-016-0021.

Nosek, B. A., Alter, G., Banks, G. C., Borsboom, D., Bowman, S. D., Breckler, S. J., ... \& Yarkoni, T. S. (2015). Promoting an open research culture. Science, 348(6242), 14221425 https://doi.org/10.1126/science.aab2374

Nosek, B. A., Ebersole, C. R., DeHaven, A. C., \& Mellor, D. T. (2018). The preregistration revolution. Proceedings of the National Academy of Sciences, 115(11), 2600-2606. https://doi.org/10.1073/pnas.1708274114

Open Science Collaboration. (2015). Estimating the reproducibility of psychological science. Science, 349(6251). https://doi.org/10.1126/science.aac4716

Parsons, S., Azevedo, F., Elsherif, M. M., Guay, S., Shahim, O. N., Govaart, G. H., Norris, E., O’Mahony, A., Parker, A. J., Todorovic, A., Pennington, C. R., Garcia-Pelegrin, E., Lazić, A., Robertson, O. M., Middleton, S. L., Valentini, B., McCuaig, J., Baker, B. J., Collins, E., ... Aczel, B. (2021) A Community-Sourced Glossary of Open Scholarship Terms [Manuscript submitted for publication]. Department of Experimental Psychology, University of Oxford.

Pownall, M. (2020). Pre-Registration in the Undergraduate Dissertation: A Critical Discussion. Psychology Teaching Review, 26(1), 71-76.

Pownall, M., Talbot, C. V., Henschel, A., Lautarescu, A., Lloyd, K. E., Hartmann, H., Darda, K.M., Tang, K.T.Y., Carmichael-Murphy, P. \& Siegel, J. (2021). Navigating Open Science as Early Career Feminist Researchers. Psychology of Women Quarterly. 
Sacco, D. F., \& Brown, M. (2019). Assessing the efficacy of a training intervention to reduce acceptance of questionable research practices in psychology graduate students. Journal of Empirical Research on Human Research Ethics, 14(3), 209-218. https://doi.org/10.1177/1556264619840525

Sarafoglou, A., Hoogeveen, S., Matzke, D., \& Wagenmakers, E. J. (2020). Teaching good research practices: Protocol of a research master course. Psychology Learning \& Teaching, 19(1), 46-59. https://doi.org/10.1177/1475725719858807

Stojmenovska, D., Bol, T., \& Leopold, T. (2019). Teaching Replication to Graduate Students. Teaching Sociology, 47(4), 303-313. https://doi.org/10.1177/0092055X19867996

Smith, M. S. (2009). Opening education. Science 323(5910), 89-93. https://doi.org/10.1126/science. 1168018

Strand, J. F., \& Brown, V. A. (2019). Publishing open, reproducible research with undergraduates. Frontiers in Psychology, 10, 564. https://doi.org/10.3389/fpsyg.2019.00564

Tierney, W., Hardy III, J. H., Ebersole, C. R., Leavitt, K., Viganola, D., Clemente, E. G., ... \& Hiring Decisions Forecasting Collaboration. (2020). Creative destruction in science. Organizational Behavior and Human Decision Processes, 161, 291-309. https://doi.org/10.1016/j.obhdp.2020.07.002

Tierney, W., Hardy III, J., Ebersole, C. R., Viganola, D., Clemente, E. G., Gordon, M., ... \& Culture \& Work Morality Forecasting Collaboration. (2021). A creative destruction approach to replication: Implicit work and sex morality across cultures. Journal of Experimental Social Psychology, 93, 104060. https://doi.org/10.1016/j.jesp.2020.104060

Topor, M., Pickering, J. S., Barbosa Mendes, A., Bishop, D. V. M., Büttner, F. C., Elsherif, M. M., ... Westwood, S. J. (2020, December 14). An integrative framework for planning 
and conducting Non-Intervention, Reproducible, and Open Systematic Reviews (NIROSR). https://doi.org/10.31222/osf.io/8gu5z

Wagge, J. R., Brandt, M. J., Lazarevic, L. B., Legate, N., Christopherson, C., Wiggins, B., \& Grahe, J. E. (2019). Publishing research with undergraduate students via replication work: The collaborative replications and education project. Frontiers in psychology, 10, 247. https://doi.org/10.3389/fpsyg.2019.00247

Wilkinson, M. D., Dumontier, M., Aalbersberg, I. J., Appleton, G., Axton, M., Baak, A., ... \& Mons, B. (2016). The FAIR Guiding Principles for scientific data management and stewardship. Scientific data, 3(1), 1-9. https://doi.org/10.1038/sdata.2016.18 